\title{
Fundamentos filosóficos de la crítica ellacuriana al movimiento revolucionario
}

- Luis Alvarenga

\section{Introducción}

Los movimientos de liberación parecen ser cosa del pasado en las sociedades globalizadas de hoy en día. Se pretende hacer ver a esta época como "el fin de las utopías", dado el fracaso de los regímenes socialistas en Europa (Oriental, cl descalabro del sandinismo y la precariedad en la cual se debate la Revolución cubana. En El Salvador, esta posición toma fuerza por cuanto la izquicrda ha dejado de ser un agente de cambios sociales y se ha diluido en una dinámica electoral que se ha impuesto, por el momento, a todas sus posibilidades transformadoras.

Sin embargo, la necesidad de liberación sigue patente. El capilalismo neoliberal y globalizante no ha respondido a los problemas de miscria, hambre y anallabetismo de sectores cada vez mayores. Proponer un pensamiento y una praxis liberadoras implica asumir esa realidad. En ese sentido, el pensamiento filosófico, teológico y político de Ignacio Ellacuría tienen una importancia capital. Para llegar a un pensamiento y a una praxis liberadora que esté a la altura de nuestros tiempos, es preciso emprender una tarea crílica. Ellacuría lo hizo hasta sus últimas consecuencias. El propósito de este trabajo es el de mostrar cómo la crítica de Ellacuría hacia el movimiento revolucionario de El Salvador en las décadas de los setenta y ochenta del siglo XX está ligada íntimamente a su concepción filosófica de liberación. Todo ello, con el objeto de reivindicar un pensamiento que tiene mucho de revolucionario, en un sentido pleno y vivificante. 
En este trabajo buscaremos, en un primer momento, definir, desde las calegorías ellacurianas la liberación. Esto no puede lograrse, como ya se verá, si no partimos del concepto de realidad histórica, ya que son dos conceptos muluamente imbricados. Ilecha esta fundamentación teórica, pasaremos a analizar sus cuestionamientos al movimiento revolucionario, hechos en editoriales, arlículos y pronunciamientos públicos. Finalmente, intentaremos enunciar algunos de los aportes que esta crílica ofrece a la lucha por la liberación en el presente.

\section{Realidad histórica y liberación}

Para llegar al fundamento filosófico de las críticas de Ignacio Ellacuría al movimiento revolucionario, es preciso saber cuál es el concepto ellacuriano de liberación. Sin embargo, hacer esto implica partir de otro concepto: el de realidad histórica. Realidad histórica y liberación son, en Ellacuría, dos conceptos muluamente imbricados. No puede entenderse la liberación prescindiendo, pues, del concepto de realidad historical.

\subsection{El concepto de realidad histórica}

Realidad histórica es un concepto que no puede entenderse sin comprender el signilicado que en Ellacuría tiene la calegoría de realidad. Iis de sobra conocido que Ellacuría parte de los aportes de Xavier Zubiri para elaborar este conceplo.

En Zubiri y Ellacuría, el concepto de realidad implica una novedad lilosófica con respecto a algunos de sus predecesores. En mucha de la tradición del pensamiento occidental nos encontramos con conceptualizaciones que colocan a la realidad totalmente fuera del sujeto (Ios distintos materialismos y el platonismo), o dentro de este (Ios racionalismos). Estas conceptualizaciones parten de una visión dual y escindida: cuerpo y alma, sujeto y objeto, absiracto y concreto. Optan por colocar la densidad de lo real en uno de los dos términos duales. El otro término simplemente es ilusión (Lo sensitivo, con respecto a Platón). o se reduce únicamente a rejlejar lo real (algunos materialismos). En Zubiri y Ellacuría encontramos una superación de este dualismo.

¿Cómo se da esta superación? Al alirmar que el ser humano, en virlud de sus notas constitutivas, se encuentra instalado en la realidad. No es necesario, como quería Descartes, establecer un puente entre el sujeto y el objeto para dar con la realidad. El ser humano es un animal de realidades. Dice Xavier Zubiri:

El hombre es una realidad sustantiva, esto es, un sistema clausurado y total de notas constitucionales psico-orgánicas. Una de ellas es la inteligencia, esto es, la aprehensión de todo y de sí mismo, como realidad. Es, a mi modo de ver, la esencia formal y constitutivamente sentiente: primaria y radicalmente, aprehende lo real sintiendo su realidad. Gracias a esta inteligencia 
sentiente, el hombre se comporta con todas las cosas reales, y consigo mismo, no sólo por lo que determinadamente son en sí mismas, sino que se comporta con todo por ser real y en cuanto es real: vive de la realidad. Es animal de realidades. En su virlud, el carácter de realidad del hombre es un momento determinante de su acción: el hombre actúa realmente porque es "su" realidad."

Ser animal de realidades implica varias cosas. Primero, que el ser humano es un animal. Señalar esto es de especial importancia para este trabajo. En la visión zubiriana-ellacuriana del problema quiere decir que hay un componente, biológico muy importante para entender al hombre y también a la realidad, que es lo que compete a este trabajo. La naturaleza no está separada ni del hombre, ni de la realidad, ni de la historia. Tiene, como será explicado más adelante, una especial relación con ellos, una relación que no es necesariamente de oposición ni de subordinación.

El que el hombre sea animal de realidades implica, en segundo término, que, el ser humano aclúa dentro de la realidad en virlud de sus opciones. Los demás animales, gracias a sus nolas constituyentes, operan sobre la base de estímulos. La estimulidad es lo que define ese acluar. Estimulidad implica tener un elenco preciso y enclasado de respuestas frente a estímulos concrelos. El ser animal de realidades implica que, ante una situación determinada, la gama de respuestas es amplia y compleja: Esta gama es abierla. La aperlura será una nota fundamental de la realidad. Ello no implica, empero, que en el animal de realidades la estimulidad está superada tolalmente. Hay que recalcar que los componentes biológicos, naturales, no son ajenos al hombre y a la realidad. El ser humano liene esa característica de ser animal de realidades por algo que lo distingue frente a los demás animales: Lo que Zubiri llama inteligéncia sentiente. Esto implica que tiene una "impresión de realidad" gracias a sus sentidos. Pero esa sensorialidad no está divorciada de la inteligencia. Son una unidad estruclural. No hay tal dualidad entre sentir e inteligir en Zubiri y Ellacuría. En su tesis sobre el pensamiento ellacuriano, lléclor Samour lo explica de esta manera: "Inteligir y sentir son sólo dos componentes o momentos de una única estructura que ejecuta un acto único y complejo, el acto de intelección sentiente. No se trata, por tanto, de una mera continuidad entre sentir e inteligir ni de una unidad objetiva en el sentido de que ambos versaran sobre el mismo objeto, sino de una unidad estruclural y sistemálica: el momento sentiente es la presentación impresiva del contenido del acto, aquello por lo que las cosas se nos presentan: el momento intelectivo es, en el sentir humano mismo, el momento modal de la impresión, la formalidad de realidad"'-

Es necesario apuntar que la realidad se basa en la actualidad, entendiendo esta palabra como "una especie de presencia física de lo real". La manera en que el ser humano está instalado en la realidad parte de esa presencia física,

Fundamentos filosóficos de la critica ellocuriana al movimiento revolucionario 
pero esa instalación no es meramente contemplativa, sino que implica una actividad por parte del humano: "Como viviente, el hombre se halla entre cosas, externas e intemas, que lo mantienen en aclividad constante y primaria; el viviente es así "constitutiva actividad. El viviente está colocado entre las cosas, tiene su locus propio entre ellas, pero al mismo tiempo está dispuesto o situado en determinada forma frente a ellas, pero de modo que su situación se apoya en su colocación. El viviente, así colocado y situado, se halla en un determinado estado vital"4, afirma Ellacuría.

Hemos dicho, en líneas anteriores, que lo que distingue al ser humano frente a los otros animales es el poder optar ante la realidad. Pero esta opción, acto supremo de libertad, tiene a su base las notas biológicas del ser humano. Ellacuría asevera: "Las cosas, entre las cuales está el viviente, modifican el estado vital y a esa modificación responde el viviente, con lo que adquiere un nuevo estado"s. La modificación del estado vital tiene tres momentos: suscitación (esto es, suscitar una acción), afección (alteración del tono vital del viviente) y respuesta. $\wedge$ esto, Zubiri le llamará comportamiento, y este comportamiento expresará un nivel de control sobre las cosas. En lo que respecta a estos momentos de suscitación, afección y respuesta, el ser humano no se diferencia en nada a los animales. Sin embargo, el humano posee una estructura psico-orgánica que lo capacita para que estos momentos transciendan lo meramente estimúlico y su enfrentamiento con las cosas sea en tanto realidad.

Ahora bien, si el enfrentamiento con las cosas en tanto realidad es opcional, esto deja abiertas varias interrogantes: ¿Es ese enfrentamiento meramente opcional? ¿Hay determinaciones en la realidad a las que está sujeto el ser humano? Estas preguntas han sido objeto de debate filosófico. Algunas de las respuestas se han decantado por algún tipo de reduccionismo: $\mathrm{O}$ bien, el ser humano hace la realidad a la medida de sus opciones (individualismo, voluntarismo), o bien, las circunstancias de la realidad condicionan por completo al ser humano (el materialismo dialéctico).

La realidad se impone a la inteligencia. Tiene una fucrza de imposición por su carácter "de suyo". La inteligencia, por su parte, no está subyugada a la "suidad" de lo real: tiene, como ya dijimos, la capacidad de opción. Por otro lado, la realidad no es un "todo monolítico" contrapuesto a la inteligencia. La realidad se caracteriza por tener unas notas (biológicas, personales, sociales, históricas, etc.), cada una de ellas relacionadas estructuralmente con las demás, en una mutua "respectividad" hacia el resto. Realidad e inteligencia guardan una relación muy especial, totalmente ajena a visiones deterministas o racionalistas. "Es imposible ---dice Zubiri- una prioridad intrínseca del saber sobre la realidad, ni de la realidad sobre el saber. El saber y la realidad son en su misma raíz estricta y rigurosamente congéneres"'. Por ello, la insistencia en esa relación entre el hombre ---como animal dotado de inteligencia sentiente- y realidad. 
No hay una "realidad en sî" —así como las "cosas en sî" del sistema kantiano, sino que esa realidad se da —entendida como una estructura de posibilidades- con relación a la inteligencia. No significa eso que sin hombre lo demás sería irreal: significa solamente que no se daría ese enfrentamiento con esc lo demás en tanto realidades.

Ahora bien, si la realidad es una estructura, hay que decir también que se trata de una estructura dinámica, en perenne transformación. Su carácter estructural se basa en la materia, a la cual, explica Ellacuría, "le compete un dinamismo intrínseco, al cual se debe, así como a la respectividad unitaria del cosmos, el movimiento y el cambio. No hay por qué buscar una razón distinta al movimiento de la materia, que a la existencia de la materia; admitida ésta, tal como se nos presenta, ha de admitirse que la materia es dinámica por ser material. Como este dinamismo es el dinamismo de una estructura, que es respectiva y que es cursiva, tiene que aparecer en forma de movimiento y de cambio. Para explicar el movimiento, no se requicre, por tanto, ni un motor fucra de la materia ni que esta materia esté estructurada dialéclicamente, si por dialéctica ha de entenderse una unitaria oposición de contrarios"7

La Iransformación de realidad signilica un "dar más de sî”, es decir, la aparición de nuevas y más radicales formas de realidad. Los estudios científicos de Zubiri, que Ellacuría comenta con amplitud en los primeros capílulos de Filosofía de la realidad histórica, dan cuenta cómo la malteria va evolucionando, merced a un proceso de especialización y de creación de nuevas estructuras: desde la materia inorgánica hasta el surgimiento de lo biológico; de estrucluras biológicas con un creciente grado de complejización, hasta el surgimiento del ser humano, cuya "novedad", por así decirlo, se basa en su estructura psico-orgínica. Zubiri hace un recorrido, además, por el desarrollo de esa nueva realidad -la humana-, que abre las puerlas a una nueva dimensión de lo real: la historia. Vale decir que cada lorma nueva de realidad no anula a las anteriores: estas quedan "subtendidas dinámicamente" por las formas nuevas. Pero no soilo hay formas nuevas de realidad, dice Ellacuría: De hecho hay mois realidad. I a realidad es, pues, procesual: cada forma de realidad procede y se apoya de otra, y, a su vez, proyecla nuevas y mayores formas de realidad.

En una síntesis sobre las tesis ellacurianas sobre la realidad histórica, Samour explica: "La realidad superior, el más de realidad, no se da separada de lodos los momentos anteriores del proceso real. Se da, pues, un más dinamico de la realidad, desde, en y por la realidad inferior, de modo que ésta se hace presente de muchos modos y siempre necesariamente en la realidad superior. Fise estadio último de la realidad, en el cual se hacen presentes todos los demís, es al que se llama realidad histórica. La realidad histórica es la realidad entera asumida en el reino social de la libertad; es la realidad mostrando sus más ricas virlualidades y posibilidades desde el subsuclo de la realidad histórica"x.

Fundamentos filosóficos de lo critica ellacuriono al movimiento revolucionario 
La realidad histórica influye en las restantes formas de realidad (biológica, personal, social, etc.), de distinto modo. A la par de ello, esas formas, subtendidas dinámicamente, también influyen en la dinámica procesual de la hisioria. Y esta mutua influehcia o, mejor aún, imbricación, se da de manera estruclural. En cuanto la realidad histórica es forma superior de realidad, Ellacuría prefiere utilizar este término y no tanto el de historia.

La historia se distingue, según Ellacuría, por poseer una serie de características que la distinguen de otro tipo de realidad. Todo ser humano está, por sus notas constitutivas, vertido a la especie (phylum) humana: es la versión filética. El phylum es, para Ellacuría, "el cuerpo material de la historia". Sin phylum no es posible hablar de historia. Gracias a esa versión, podemos vislumbrar una primera nota de la historia: es un proceso de Iransmisión Iradente. Es transmisión, por cuanto de generación en generación se transmiten una seric de rasgos genéticos, que hacen que el phylum siga existiendo como tal. Es Iradente, porque la generación precedente entrega a la nueva una tradición: formas de vida, esto es, formas de estar en la realidad. Y decir formas de esiar en la realidad implica algo más: implica posibilidades sobre las cuales optar y crear nuevas formas de realidad. Con el término posibilidades, hay que incluir la siguiente precisión de Ellacuría: "las posibilidades son siempre posibilidades de vida, posibilidades de historia y están orientadas a las formas de estar en la realidad"'". Posibilidad no implica que cualquier cosa es posible: "las posibilidades no se fundan en sí mismas, sino en lo posible. La razón, en definitiva, es que la vida no radica en sí misma, sino en la realidad física que vive. (), dicho desde otro punto de vista", la vida no puede lantasear posibilidades sin cuento, porque sólo serán realmente tales, aquellas que sean realmente posibles”...

La tradición implica varios momentos estructuralmente relacionados. Un primer momento, es el momento constituyernıe: Lin él se val constituyendo ese modo de estar en la realidad que seré entregado de una generación a otra. Fa segundo momento, es el momento contimamte: "Porque lo que se entrega -explica Ellacur ía- es una forma de estar en la realidad y porque quien recibe es una esencia abierla, pero sentientemente abierlat, la tradición continúa. Es continuante" sin embargo, no sólo porque continuia lo que se le ha dado, esto es, hace que siga lo recibido, sino porque forzosamente lo impulsa hacia delante, lo cambia"'t. Viene un tereer momento: el progredicente. El ser humano no es un mero receptor pasivo de la tradición. Dado su carácter prospectivo, Iomarí esa tradición como conjunto estruclurado de posibilidades, a partir de las cuales buscará su realización. En la medida que estas posibilidades posibiliten esa realización, serán posibilidades posibilitanıes. La busqueda de la realización, la búsqueda del proyecto de vida. se apoyará en las posibilidades recibidas, pero a su vez, buscará crear otras nuevas. De ahí que es imporlante recalcar que en la realidad histórica, el sujeto no aparece de la nada: es parte de un proceso y está condicionado por esa realidad, pero lampoco está subyugado por las condiciones históri- 
cas. Hay un margen de creación muy importante, que es una de las cosals que hace que la realidad histórica vaya tomando nuevas formas. Ese margen de creación se basa en el hecho de que la realidad histórica es transmisión de posibilidades: "Posibilidades no es aquí aquello que no es imposible, ni siquiera aquello que es positivamente posible, sino aquello que posibilita. $Y$ posibilitar consiste formalmente en dar un poder sin dar una necesidad lija y unidireccional de realización de ese poder. Aquí, el poder es optar. Las posibilidades no dan el poder para oplar, pero sí dan el poder oplar; el poder para oplar es algo que el individuo humano trae consigo, pero para poder optar con ese poder de opción se requieren estrictas posibilidades posibilitantes. Esta distinción fundamental resuelve el problema del reconocimiento formal de la libertad que no se apoya en la posibilitación real de las condiciones de esa libertad: si se tiene el poder para oplar, pero no se puede oplar, porque no se cuenta con posibilidades reales se está negando la libertad humana, la libertad histórica ${ }^{15 " . .}$

El hecho de la posibilitación transforma tambićn al suljeto: "Lo posibilitado significa, entonces, que un sujeto no sólo está ya facultado para hacer algo, que sus potencias ya están en facultad de hacerlo, sino que cuenta con un factor, que siendo en principio extraño, es indispensable para, mediante su apropiación "poder hacer" lo que antes no podía: no sólo está facultado, sino que está posibilitado, está realmente posibilitado sin que esa posibilitación implique la adquisición de una nueva nota ni constitutiva ni adventicia"l". Ellacuria menciona otro elemento de importancia. Las facultades humanas que pueden hacer que el ser humano se apropie de nuevas formas de realidad son las capacidade's. "Capacidad —dice Zubiri- es la potencia y facultad en cuanto principio más o menos rico de posibilitación. Capacidad es formalmente capacidad de posibles (en el sentido preciso en que aquí empleo este vocablo). La capacidad es más o menos rica según sea mayor o menor el ámbito de lo posible que constituye ${ }^{1 \% . . .}$. En el sentido de ser un proceso de adquisición de capacidades para apropiarse de nuevas realidades, "la historia es un proceso físico y melafísico de capacitación ${ }^{1 \times " . ~ A l ~ d i n a m i s m o ~ h i s t o ́ r i c o ~ c r e a d o ~ p o r ~ l a ~ p o s i b i l i t a c i o ́ n ~ y ~ l a ~ c a p a c i t a c i o ́ n ~ — e s ~}$ decir, que constituye el momento de libertad humana y que es parte de la realización de la humanidad - se le llama praxis. La praxis es toda acción que conduce a un incremento de realidad y solamente se da en el ámbito de la realidad histórica. Decir esto, empero, no implical un concepto que reduce el término a lo meramente político o económico: "La praxis se identifica así con el proceso histórico mismo, en cuanto este proceso es produclivo y transformativo. La reducción de la praxis a una determinada producción de condiciones materiales o a una determinada transformación de las estructuras sociales y políticas es arbitraria. Hay una praxis lúdica, etc. Desconocerlas, sería desconocer el carácter estructural de la historia y la pluralidad de fuerzas que operan sobre ella. Que unas formas de praxis, por ejemplo, la praxis política o la praxis económica, puedan tener mayor eficacia puedan tener mayor eficacia inmediata en algún

Fundamentos filosóficos de la critica ellacuriana al movimiento revolucionario 
lipo de transformación de la sociedad, no es prueba de que la hayan de tener siempre, ni menos aún, que agoten loda la necesidad de transformaciones reales ${ }^{10 \%}$. Como la visión ellacuriana es abierla, esto es, no admite determinismos absolutos de hinguna clase, da su silio en el concepto de praxis al individuo, contrario a los dogmas de cierla izquierda: "El olvido de la dimensión personal de cualquier praxis, realmente humana, no puede menos de alienarla y convertirla en manipulación de objelos, en naluralización personas. En la praxis histórica es el hombre entero quien toma sobre sus hombros el hacerse cargo de la realidad, una realidad deviniente, que hasta la aparición del primer animal inteligente se movía exclusivamente a golpe de fuerzas físicas y de estímulos hiológicos"-a". Advierte lambién contra desviacionismos idealistas o crasamente malerialislas, y reitera su visión estruclural de la realidad: "La praxis histórica es una praxis real sobre la realidad, y éste debe ser el criterio último que libere de toda posible mistificación: la mistificación de una espiritualización que no liene en cuenta la materialidad de la realidad y la mistificación de una materialización que tampoco tiene en cuenta su dimensión trascendental. La consideración unilaria de lodos los dinamismos que intervienen en la historia muestra a las claras la complejidad de la praxis histórica y los supuestos requeridos para que séa plenamente praxis histórica'”".

Se tiende a identificar a la praxis como algo opuesto a la claboración teórica, de tal suerte que la primera se reduciria a una suerte de activismo, mientras que la scgunda se degradaría a la mera contemplación. Esta visión antagonista y reducida de los términos, queda corregida cuando Ellacuría plantea: "Ffectivamente, la teoría no se opone a la praxis. Desde luego, no era así en Aristóteles, donde la oposición era entre praxis y poiesis y no entre praxis y leoría. El sentido aristotélico de la praxis como inmanencia podría ser recuperado si entendemos la realidad social e histórica como un todo, porque entonces la inmanencia de la praxis socio-histórica se mantendría, y cobraría el pleno sentido de autorrealización. Por eso, no me parece adecuado hablar de praxis teóricas, de praxis científicas, etc. La praxis es la unidad de todo lo que el conjunto social hace en orden a su transformación e incluye dinámicamente la respectividad del sujeto-objeto, tal como antes lo entendimos. Esa praxis tiene momentos teóricos de distinto grado que van desde la conciencia refleja y la reflexión sobre lo que es, lo que sucede y lo que se hace; reflexión que puede tomar distintas formas, desde las pre-cientificas hasta las estrictamente científicas, según la peculiaridad de cada una de las ciencias'-”.

De esta manera, como dice lléclor Samour, "la praxis queda caraclerizada con una densidad melafísica enorme, por cuanto en ella no sólo estí en juego el destino de la humanidad y de los diversos grupos humanos, e incluso el de la historia misma, sino, más radicalmente, la realización misma de la realidad en tanto que realidad, es decir, su constilución transcendental. La gravedad de este hecho estriba en que por el mismo carácter de la praxis, sustentada en el dina- 
mismo de posibilitación y capacilación de los seres humanos, aquello no esta predeterminado ni asegurado de antemano. Ello plantea el problema de cuíl sea la praxis histórica adecuada, en cada momento del proceso histórico, para posibilitarlo y realizarlo" "'. Desde esta perspectiva, la praxis histórica que cobrara un valor metafísico mayor será la praxis liberadora, por cuanto esta posibilita más realidad. Ese será el punto central del siguiente apartado.

\section{El concepto de liheración en Ellacuría}

Ellacuría da al término liheración una connotación novedosa. Normalmente, este término va asociado con problemas políticos o sociales. No es que en Ellacuría esta veta se pierda. Sucede que ahora cobra nuevas dimensiones.

Cuando Ellacuría traza el recorrido de Zubiri hace para lundamentar sus tesis sobre la vida, nos estí alirmando que la liheración se da, en primer lugar, como parte de las dinámicas naturales. En la evolución se da un proceso de transformaciones biológicas en orden a responder a necesidades del medio. Se da un momento que Zubiri llama de desgajamiento exigitivo: llay una necesidad impuesta por el medio al viviente que éxige una transformación en el organismo. A este momento, le sucede el de liberación: "una "liberación" de nuevas estructuras y comportamientos: es una liberación "de" lo que tenía que hacer la especie inferior para seguir viviendo, dada su nueva condición transformada, pero es una liberación "para" - no en sentido linalístico, sino en sentido puramente resultalivo-- que quede estabilizada la nota (estructura o comportamiento) en cuestión 24". EI momento que sigue es el de la suhlénsión dincimica: Ia estructura anterior no queda anulada en la nueva, como explicamos anteriormente.

La liheración no se da únicamente en el ámbito de la evolución de las especies. No es así, porque representa un proceso de expansion de las posibilidades y capacidades: es un proceso que se da en las distinlas formas de realidad. En un segundo instante, por así decirlo, la liberación se da en el surgimiento de la historia a partir de la naturaleza. El ser humano, como ya se dijo, conserva, subtendidas dinámicamente, muchas de las notas de los demás animales. $\wedge$ partir de esa subtensión dinámica de lo biológico, aparecen nuevas lormas de realidad: I a aparición de las sociedades, etc.: "Én el hombre se conserva el carácter de estímulo, por más que para él los estímulos estén aprehendidos como reales. Consiguientemente, vivir en sociedad, desde este elemento vinculante de la especie, no supone ya la constitución de la relación perfecta entre los hombres; es tan sólo contar con la posibilidad real y la necesidad efectiva para hacer algo, siempre abierto, que sólo al final podría llamarse sociedad humana rectamente constituida $25 "$. Viene aquí el momento de liberación: "El hombre social y la sociedad humana serán resultado de la historia y no puro regalo de la naturaleza, que exigirá el desgajamiento de la historia y que se mantendrá en ella como subtensión dinámica, sin la cual la historia humana dejaría de ser lo que es"

Fundamentos filosóficos de lo críico ellocuriano al movimiento revolucionario 
Liberación no implica, como ya se dijo, anulación de la naturaleza: "La liberación de la naturaleza no es, por tanto, como quería Ilegel, una separación de la naturaleza, porque la naturaleza sigue estando presente en la realización de lo más estrictaménte histórico. A su vez, la liberación de la historia, es decir, la historia como proceso de liberación, es, hasta cierto punto, una liberación de la naturaleza, pero de ninguna manera su negación; es liberación cada vě mayor, nunca total, de los elementos necesitantes naturales, pero nunca su aniquilación. $\mathrm{Ni}$ el hombre es concebible sin su cuerpo, ni la sociedad sin la especic, ni la historia sin la naturaleza":?

La praxis histórica produce, como habíamos dicho antes, nuevas y mayores formas de realidad. En ese sentido, la humanidad ha venido adquiriendo mayores poderes y capacidades a lo largo de la historia, como producto de su praxis. ¿Hay que dar por descontado que la praxis histórica, con toda la adquisición de facultades y poderes que conlleva, camina hacia mayores grados de humanización? Ellacuría advertía que no toda praxis histórica va hacia esos fines: "ison los poderes desarrollados los verdaderos poderes que necesita la humanidad para humanizarse? ¿No se habrán desarrollado unos poderes con mengua y aun aniquilación de otros poderes más importantes? ¿Está ascgurado que los poderes actuales no dejen un día de serlo? ¿No ha habido en las historias particulares de los pueblos rutas falsas en el acrecentamiento de su poder que los han llevado a su destrucción o, al menos, a su empobrecimiento? Tal vez. sea probable que, tomada la historia y la humanidad en su conjunto, sólo vayan a subsistir y prosperar aquellos poderes y aquellos sujetos del poder que sean efectivamente los más "poderosos", pero equiparar los poderosos y los triunfantes con los "mejores" es muchas veces un artilugio falaz. Y eso, incluso cuando no se plantea el problema ético de lo que es mejor y se mantiene la cuestión en términos puramente históricos: los poderes pueden ser utilizados para construir, pero también para destruir: he ahí el riesgo constitutivo de la historia. Los peligros apuntados por los ecologistas y las lamentaciones de los males que surgen en los países superdesarrollados representan una llamada de atención. Y, sobre todo, constituyen una gravísima llamada de atención los tremendos costes sociales que implica el desarrollo de poderes en manos de quienes se estiman la vanguardia de la historia, la punta de lanza del avance histórico. I a apertura de la historia es así un desafío para el hombre: puede avanzarse indefinidamente hasta que la naturaleza no soporte ya más la carga de la historia. Y esto es una posibilidad real con la cual ha de contar la historia $2 \times "$.

La conclusión evidente es que la praxis que posibilita un proceso de liberación en la historia será la praxis liberadora. Pero, ¿qué implica liberación en el campo de la historia? ¿Liberación de qué? ¿Quiénes son los sujetos de esa liberación? ¿Cómo se relaciona este concepto con otros conceptos de liberación o de libertad? 
"En primer lugar —escribe Ellacuría en un trabajo de 1985-, la liberación está orientada en función del proceso y el proyecto de posibilitar que los hombres scan actores y autores de su propio proceso histórico. Se tralla de crear condiciones en las que, por su carácter, se exija que los hombres den mís de sí. liberen lodas sus potencialidades. IEn segundo lugar, hay que insistir que la liberación es un proceso. "Un proceso que en lo personal es, fundamentalmente, un proceso de conversión y que en lo histórico es un proceso de Iransformación. cuando no de revolución"."'.".

Por lo tanto, la liberación en el ámbito histórico implica liberar al ser humano de lo que mantiene oprimidas sus potencialidades y que, a su vez. le impide ser "actor y autor" de su propio destino. En el contexto mundial, pero más específicamente en el contexto latinoamericano, hay una seric de estructuras de poder político, económico y social, históricamente delerminadas, que impiden que las mayorías populares sean protagonistas y creadores de su propia historia. La dominación capitalista restringe el desarrollo de las potencialidades a unos pocos, en detrimento de grandes secerores de la población de nuestros páises. Esa es la realidad histórical que fillacuría tenía en mente al proponer el concepto de liberación. El contexto latinoamericano del que parte lillacuría es el de la existencia de países subdesarrollados. "Sobre este lereer Mundo las naciones dominantes proyectan sus estructuras de producción y sus estructuras de consumo, mediante la producción de plusvalía y su realización en el mercado, para lograr la apropiación del exeedente económico. Es esta realización de la plusvalía en el mercado lo que cierra el proceso y manifiesta lo que es la llamada sociedad de consumo. Por lo que toca a la producción pone en juego factores capitales de la realización humana y por lo que toca al consumo duplical las condiciones de dominación (...) En su más cruda verdad, la sociedad de producción. están consumiendo al hombre y al mundo, lo están deshaciendo "il.".

La liberación, por consiguiente, no se da en el vacío. Iss una tarea siluada histórica y socialmente, en un contexto concreto. Parle, pues, de unas estructuras reales, de un eontexio real en el que toman parte fuerzas sociales concrelas: "La liberación de los pueblos así como su opresión antecedente las hacen las fuerzas sociales. Un individuo puede oprimir y reprimir a un individuo o a un grupo de ellos. Pero, cuando ya se trata de puchlos enteros, son fuerzas sociales las que realmente llevan los procesos de opresión y de liberación. Las fuerzas sociales que, en principio, más pueden contribuir a la liberación son las que constiluyen la contradicción principal de las fuerzas que son las responsables principales de a dominación y de la opresión" ".

Las estructuras de dominación y opresión, así como las fucrzas sociales que actúan a través de esas estructuras, son la confirmación de lo que Ellacuría cataloga de pecado hisiórico y social. Esta definición proviene, obviamente, de la teología. Sin embargo, nos interesia, porque pecado en este contexto implica

Fundamentos filosóficos de la critico ellocuriono al movimiento revolucionario 
negación: Negación de la vida, negación de la plenitud, de la realización de la humanidad. En un escrito teológico de 1987, asevera: "La liberación del pecado histórico y social en cuanto configuración pecaminosa y pecaminante de las estructuras y de los procesos históricos es también un proceso en que intervienen conjuntamente Dios y el hombre por el mismo carácter social e histórico de ese pecado; en cuanto pecado social e histórico no es atribuible directa e indirectamente a ningún hombre en particular, pero no por ello deja de ser ocultación positiva de la verdad de Dios y positivo intento de anulación de la plenitud de vida que Dios quiere comunicar a los hombres. Es en esta dimensión del pecado donde ocurre la necesidad de la transformación de las estructuras, precisamente en lo que éstas tienen de ser efecto del pecado y causa de nuevos pecados. Por más que este triple pecado, el original, el social y el personal, sólo analógicamente entren en el mismo concepto de pecado, no por ello dejan de ser estrictamente pecado, que necesitan de salvación divina en forma de liheración. Son efectivamente dominadores y opresores del hombre y de la humanidad, son negación de la imagen divina en el hombre y son la barrera fundamenlal entre el hombre y Dios, de unos hombres con olros y del hombre con la naluraleza"'?

Esa estructura de opresión impide, pues, que las mayorías latinoamericanas puedan apropiarse de mayores "posibilidades posibilitantes". No pueden estas mayorías aspirar a realizarse, porque no cuentan con las condiciones materiales mínimas que aseguren su supervivencia, ya no digamos una vida digna. Por otro lado, el capitalismo hace del tener y de la dominación sobre los otros, los criterios de libertad: "Hoy, en cambio, se supone que sólo el tener-mís con referencia a tener-más-que-otros, es lo que posibilita el ser-más, el ser realmente libre. La dominación se convierte en condición de libertad. De ahí que se vaya abriendo cada vez. más el abismo entre los ricos y los pobres, entre los pucblos ricos y los pucblos pobres. Por ello, la liberación como proceso colectivo, cuyo sujeto principal son los pobres, es la respuesta cristiana al problema de la libertad colectiva que posibilita y potencia la libertad personal. No hay libertad sin liberación, no hay libertad cristiana sin liberación cristiana y ésta hace referencia esencial a los pobres y a la pobreza" ". Eso implica, pues, que la liberación sea "por lo pronto una tarea histórica y, dentro de la historia, una tarea socio-económica".".

En el párrafo anterior, vemos cómo Ellacuría define a los pohres como sujelos de la liberación. Antes de pasar a def inir qué es lo que entiende lillacuría por pobres, vale la pena anticipar algunas consecuencias de esla alirmación. Primero, que al decir "pobres", Ellacuría coloca la liberación en un plano que Irasciende las visiones reducidas del liberalismo burgués. Segundo, que al alirmar a estos pohres como sujecos del proceso de liberación va mís alli incluso que los movimientos de liberación nacional: Para estos movimientos, el sujelo del proceso de liberación es la vanguardia política. Sobre todo esio abundaremos más adelante. 
El concepto de pobre se remite a unas condiciones económicas claras. El problema de la pobreza tiene una dimensión económica insoslayable. Pobre serán todos aquellos sectores de la sociedad desposeídos económicamente ${ }^{35}$. El concepto de pobre va más allá del de proletariado de la tradición marxista:

Fuera de que en la experiencia en América Latina, sea por la importancia relativa del proletariado en muchos lugares, sea por el comportamiento del mismo, no constaba la importancia del proletariado, éste no coincide con el pobre al concebirse en términos tomados de una determinada relación salarial: a) los pobres están en la escala económica por debajo de los proletarios o, al menos, algunos de cllos y en gran número lo están; b) el proletariado de los países ricos adquiere respecto de los países pobres características de explotadores.

No se excluye que el proletariado sea sujeto principal de la liberación, pero no se acepta dogmáticamente que, por serlo, sea sujeto pleno de liberación ni que lo dejen de ser otros sectores desposeídos: a) la experiencia de campesinos e indígenas, como sujelo de cambio revolucionario, rompe con ciertos dogmatismos marxistas; b) la inspiración cristiana como molor de esperanza se hace sentir con características propias que enriquecen al sujeto de la liberación."

Como dirá en su artículo función liheradora de la filosofia, escrito en 1981 , “El sujeto de la liberación es idealmente el que es en sí mismo la víclima mayor de la dominación, el que realmente carga con la cruz de la historia ${ }^{37 *}$.

Este concepto de liberación que propone Ellacuría se contrapone a olras visiones sobre el lema. En primer lugar, se contrapone al concepto de libertad de la tradición liberal. Eal liberalismo, ideología burguesa, exacerba la liberlad individual. Dicha liberlad individual se basa, ante todo, en la propiedad. Se contrapone el individuo a la colectividad: Ésta última constituye un peligro para la liberlad del primero, por cuanto el Estado debe salvaguardar la propiedad privada para bien del individuo. "La concepción liberal de la liberlad hace hincapic en que ésta liene por sujeto propio a cada uno de los individuos: es cada una de las personas la que puede ser libre y la liberlad sólo se predica formalmente de las personas individuales. Liberalismo e individualismo parecen así reclamarse mutuamente ${ }^{3 \times ” . ~ P o r ~ t a l ~ r a z o ́ n . ~ E l l a c u r i ́ a ~ a f i r m a r a ́ ~ q u e ~ e s e ~ c o n c e p t o ~ d e ~ l i b e r l a d, ~}$ liberlad de minorías, es opresora de las mayorías. Fsa liberlad es opresora históricamente: "La liberlad burguesa que subyace en muchos de los anuncios de la libertad está lundada en la propiedad privada y más en concrelo en la riqueza; sin el desequilibrio de unos pocos que tienen mucho y de unos muchos que liene poco, apenas puede hablarse de liberlad. La liberlad burguesa, que supone la liberación de la aristocracia y de las monarquías absolutas, se cimentó sobre la opresión de grandes capas sociales, que sustentaban sin liberlad el desarrollo de la clase burguesa"

\section{7}

Fundamentos filosóficos de lo críico ellacuriano al movimiento revolucionario 
La libertad burguesa no tiene cabida en el horizonte de la liberación: "no hay que identificar liberación con liberalización", comenta Samour. "Liberalización apunta a la lipertad subjetiva e individual, en el marco de la ideología liberalburguesa; en cambio, liberación hace referencia a un planteamiento más material e integral"41".

El concepto ellacuriano de liberación toma distancias también con la solución que los socialismos reales dieron al tema. En esos modelos de socialismo, el Estado, "o determinadas instancias colectivas son el sujeto propio de la libertad, porque sólo en sus manos estaría el decidir sin ser sobredeterminado por otras instancias superiores" ${ }^{11 " . ~ T a m p o c o ~ e s t o ~ e s ~ l i b e r a c i o ́ n ~ p a r a ~ E l l a c u r i ́ a . ~ " L o ~}$ esencial es dedicarse filosóficamente a la liberación más integral y acomodada posible de nuestros pueblos y nuestras personas ${ }^{42 "}$, escribió. La liberación es un proceso integral, que abarca las dimensiones individuales, colectivas, sociales y personales. Ese proceso implica, en primera instancia, una "liberación de las necesidades básicas sin cuya satisfacción asegurada no puede hablarse de vida humana, ni menos aún de vida humana digna" "4?. En segundo término, implica liberarse de las formas de opresión y represión institucionalizadas: "La liberación es (...) liberación de los fantasmas y realidades que atemorizan y aterrorizan al hombre; en ella va incluida la superación de todas aquellas instiluciones sean jurídicas, policiales o ideológicas, que mantienen a los individuos y a los pueblos movidos más por el temor del castigo o el terror del aplastamiento que por el ofrecimiento de ideales y de convicciones humanas: es lo que debiera llamarse libertad de represión, que histórica y socialmente se puede presentar de muy distintas formas ${ }^{44 "}$.

Junto a esas formas de liberación, "está la liberación tanto personal como colectiva de lodo lipo de dependencias; el hombre está condicionado en su libertad por múltiples factores y aun puede estar determinado, pero, para poder hablar de libertad radicalmente, hay que superar las dependencias, pues de poeo sirve la liberlad potencial si no puede romper las amarras del objeto que le delermina univocamente, imposibilitándole super-determinarse a sí mismo" ${ }^{"+k}$. Ts esta una dimensión personal de la liberación. que implica liberlad de dependencias que la menoscaban: el consumismo y en lin, de lodo aquello "que aparece como absoluto y que posibilita la idolatría th", esto es, de toda forma de alienación. En definitiva, de lo que se trata es que la liberación es un proceso integral que busca la libertad, no para una minoría, no para un ente colectivo que subyugue a los individuos, sino "para lodos". Ilablar de libertad para lodos es iluso si no hay justicia para esos todos. Eso denuncia el carácter ilusorio y pernicioso de la liberalización: “...aunque la liberalización parece que liene por objetivo la libertad, pretende buscarla por un camino falso que, además, pocos pueden recorer. El objetivo primario de la liberación es, en cambio, la justicia, la justicia de todos para todos, entendiendo por justicia que cada uno sea, tenga y se le dé, no lo que se supone que ya es suyo porque lo posec, sino lo que le es debido por su 
condición de persona humana y por su condición de socio de una delerminada comunidad y, en definitiva, miembro de la misma especic, a la que en su totalidad psico-orgánica corresponde regir las relaciones correctas dentro de ella misma y en relación con el mundo natural circundante. Puede decirse que no hay justicia sin libertad, pero la recíproca es más cierta aún: no hay liberlad para todos si no hay justicia para lodos" $"$ ?

\section{La crítica ellacuriana al movimiento revolucionario}

En vida, Ignacio Ellacuría fuc acusado por la derecha de ser un apologista de la guerrilla. Nada más falso. Ellacuría cjerció una crítica sistemática al movimiento revolucionario, cosa que deja en evidencia la ignorancia de quienes hicieron esos señalamientos. Ellacuría partió de una concepción del filosofar en la que el cjercicio de la crílica era central. La filosofía tenía que ejercer una función desideologizadora: desenmascarar las manipulaciones de la verdad que sirven para legitimar la injusticia estructural. Pero no solamente tendría que quedarse en este nivel. La filosofía tendría que pasar a un momento propositivo. En este contexto, la propuesta sería constituirse en una filosofía de la liberación, que estuviera comprometida con la praxis histórica liberadora. Esto último ha sido fuente de malas interpretaciones. El compromiso de la filosofía (y de toda actividad intelectual) se ha concebido como una adscripción acrílica a los movimientos revolucionarios o de liheración. También se ha entendido como una supeditación de la especificidad de la filosofía y de la labor intelectual a esos movimientos, y, además, como la reducción de esa labor a lodo aquello que tenga efectividad política inmediata. Ellacuría comprendió que era ilusorio hablar de una filosofía de la liberación si se caía en estas interpretaciones erróneas. Adscribirse dócilmente a un movimiento político, social, económico o religioso, implica para la filosofía renunciar a su caricter de crítica. Reducir el filosofar a lo inmediato, o pretender convertirse en el actor de los cambios, signilica para la filosofía el peligro de desnaturalizarse y de diluir su identidad. Probablemente, como señala Octavio Paz, la tendencia a intentar fundir la labor intelectual con la del activismo transformador, provenga de la Modernidad, y de los movimientos revolucionarios del siglo XX: "I:l revolucionario es el lipo de hombre que reúne los atributos del filósofo, del estratega y del arquiteclo social ${ }^{1 \times ”}$.

Lin lodo caso, el peligro comín es el de anular los aportes que desde la filosolía se pueden hacer a la liberacion. En ese sentido, el ejercicio de la crílica, emprendida a través de un ancilisis cue parte de la historización como punto de partida para la desideologizacion a lodo nivel, fue lo que movió a Ellacuría en su intensa labor intelectual. Si Eillacuría hubiera abandonado la especificidad del hacer filosífico y de los aportes que desde el ambito universilario podían darse. en aras de un mal entendido activismo, probablemente su visión crílica no habría ahondado tanto en los problemas de nuestra realidad histórica ${ }^{40}$. En vida, muchos le reprocharon esto a Ellacuría. Lo acusaban de acomodamiento intelec-

Fundamentos filosóficos de lo critica ellocuriono al movimiento revolucionario 
tual. Su sacrificio y el de sus compañeros y colaboradoras evidenció que su compromiso era más real y más conlundente que cualquier activismo superficial.

Por movimpiento revolucionario vamos a entender aquí a aquellas organizaciones que llevaron a cabo la lucha armada en El Salvador entre los años setenta hasta 1992, es decir, las organizaciones político militares que constituyeron al FMLN.

Como un primer paso, tracremos a cuenta algunas consideraciones que Ellacuría hace sobre el problema de la lucha armada y, a partir de ahí, intentaremos desentrañar el fundamento filosófico de sus crílicas hacia ese movimiento revolucionario.

\subsection{Las consideraciones de Ellacuría con respecto a la lucha armada}

La lucha armada fue la vía por la cual distintas organizaciones de izquierda en El Salvador y otros países de América Latina optaron para lograr transformaciones en las estructuras socioeconómicas y políticas. El viraje de eslas organizaciones hacia esa forma de lucha se da con mayor fuerza en la década de los sesenta y los setenta del siglo pasado. El triunfo de la Revolución cubana en 1959 puso en el debate de la izquierda la viabilidad de la lucha armada. La izquierda se escindió a partir de este hecho histórico. Por un lado, se encontrahan los Partidos Comunistas y por el otro, una serie de partidos y movimientos, desgajados algunos de los PC y otros, procedentes de movimientos cristianos, estudiantiles y campesinos. La mayoría de Ios PC partían de un determinado esquema leninista, heredado de una lectura descontextualizada de los texios del revolucionario ruso: concepción del proletariado de avanzada como sujelo de la revolución, lucha parlamentaria como vía de opción al poder y recurso a la vía armada, únicamente cuando se diera una correlación de fuerzas aceplables. De no concurrir un número de condiciones objetivas y subjetivas favorables, la lucha armada se constituiría en una desviación "izquierdista": activismo febril proclive al terrorismo, que no conduce a nada y, peor todavía, que justifica la represión del enemigo de clase.

Los nuevos movimientos revolucionarios estaban en contra de esta concepción "quietista". Concebían que el parlamentarismo no era concebible en una realidad como la latinoamericana, donde los aparatos represivos sofocaban cualquier disenso. Más bien, percibían que la lucha parlamentaria era una forma de Ios PC tradicionales de no encarar con seriedad el problema de la loma del poder para hacer cambios revolucionarios en las sociedades. De esta manera, surgen organizaciones armadas de izquierda, con influencias políticas variadas. No puede decirse que este movimiento armado fue uniforme: hubo organizaciones más militaristas, otras que buscaban combinar el trabajo militar con la organización política de las masas, elc. En todo caso, lo que estas organizaciones planteaban era una respuesta al problema de la lucha por la liberación en América Latina. 
Ellacuría toma una actitud crílica ante movimientos de esta naluraleza en El Salvador. Esta actitud parle del horizonte de liberación que detallamos anteriormente. Su crítica intenta ubicar a estos movimientos dentro de ese horizonte. Su abordaje dista de ser ingenuo. En primer lugar parte de la constatación que el capitalismo en América Lalina ha producido injusticia y represión y que la lucha armada, lejos de suscilar confrontaciones y odios, es una respuesta a esa realidad: “...efectivamente se eslán dando clases y lucha de clases, con el agravante de que la siluación en América Latina muestra que son las clases dominantes las que han iniciado la lucha y la violencia no sólo para construir las clases dominadas, sino para mantenerlas en la dominación, de modo que las incipientes respuestas hisıóricas de las clases dominadas son eso: respuestas a una violencia anterior, respuestas provocadas no sólo por la siluación objetiva de las clases dominadas, definida por la miseria y la injusticia, sino por la percepción de que esa siluación se dehe a la violencia cometida contra ella" s".". Desde la teología de la liberación, Ellacuría considera que no se "puede menos de aprobar y en muchos casos de apoyar a aquellos movimicntos marxistas auténticamente revolucionarios y no puramente burocráticos, sobre todo en lo que tienen de preocupación y trabajo por los pobres, tanto a la hora de la denuncia de las opresiones del sistema capilalista como a la hora de procurar elicazmente la superación de las distintas formas de miseria, injusticia y opresión ${ }^{\text {sl". }}$.

Hay un distanciamiento crílico con respecto al marxismo que inspira a los movimientos revolucionarios. Por un lado, Ellacuría considera positiva la denuncia que el marxismo hace de las injusticias del capitalismo y el que reivindique la libertad de las mayorías. Pero por otro, no acepla el que el concepto de liberación de estos movimientos se restrinja únicamente al problema de la toma del poder. También rechaza la sumisión de las organizaciones populares (cristianas, campesinas, sindicales, estudiantiles, de mujeres, etc.) a una autoproclamada vanguardia política. En ese sentido, considera que esas organizaciones tienen una especificidad que debe ser respelada, por lo que aboga por su independencia. Esto último es lógico: el pensamiento ellacuriano señala que la liberación (como proceso de plenificación humana) debe ser para todos y no sólo para un organismo colectivo que señale, desde arriba, cómo debe administrarse la libertad.

El problema del ejercicio de la violencia revolucionaria lambién es ahordado por Ellacuría. La admite como válida, únicamente si es "liberadora de las otras formas radicales de violencia, siempre que se dé en el contexto y con las condiciones debidas ${ }^{52 "}$. La violencia revolucionaria estará justificada, dado el problema de la injusticia estructural. Sin embargo, la licitud de este lipo de violencia estarí restringida, porque la violencia "siempre es un mal, y sólo puede ser usada en proporción con el mal mayor que se quiere evitar. Ese mal ha de medirse sobre todo en relación con los daños que a corla y larga distancia se den para las mayorías".

Fundamentos filosóficos de la critica ellacuriana al movimiento revolucionario 
donde lo económico es el elemento clave de toda la dinaimica histórica. En el pensamiento de Ellacuría encontramos un concepto que busca ser mais integral: la historia es estructural, esti compuesta de notas distintas (económicas, sociales, politicas, "etc.) y cada una de estas notas codetermina a las demais, en una relación de mutua respectividad. Una comprensión estructural de la historia ayuda a superar las visiones deterministas.

El determinismo histórico que forma parte de los movimientos revolucionarios está acompañada de una visión teleológica de la historia. I a historia conduee inexorablemente a la victoria de las clases revolucionarias. leste telos histórico proviene de la tradición hegeliana. Is una de las limitantes más fuertes de las concepciones del movimiento revolucionario, puesto que concluce a análisis voluntaristas de las coyunturas históricas. Son voluntaristas por cuanto parten de un supuesto: la historia favorece al proyecto revolucionario, por lo tanto, los movimientos revolucionarios pueden, en virtud de ese "lavoritismo histórico", dar por descontado que todo hecho histórico es parte de la ruta inexorable al socialismo. En 1988, el FMLN estaba convencido de que había condiciones favorables a una insurrección popular. Partía de la premisa del descontento de la población hacia la política gubernamental. Su analisis voluntarista les hizo llegar a la conclusión que ese descontento se traduciría en un alyamiento popular. la prucha de lo erróneo de este análisis se dio en la ofensiva de noviembre de 1989. La antigua guerrilla contaba con el levantamiento de la población como ingrediente complementario a la ofensiva militar en las zonas urbanas del país. No se dio tal levantamiento y la ofensiva del 89 trajo consigo costos humanos irreparables. Ellacuría escribe en 1988: "Los analistas del FMLN suponen que las condiciones objetivas del país - creciente miseria de la población, contradicciones intemas del proyecto contrainsurgente reflejadas en la crisis polílica, mayor y más radical actividad de las masas, expansión del FMI N por lodo el país, etc.- favorecen un levantamiento insurreccional de una parte imporlante de la población. Dada la dehilidad del poder estatal y dada la lortaleza del I:MLN, esto supondría la posibilidad real próxima de que el FMLN alcanzara el poder o. al menos, lograra una negociación en términos muy favorables, similares por ejemplo a los conseguidos por los sandinistas en 1979. Tal presunción respondería a un análisis científico de corle leninista. Dejando de lado si estín haciendo o no un correcto análisis leninistas de la situación, lo cual habria que ponerlo muy en duda, convendría recordar que la causalidad histórica tiene mucho de casualidad, sin olvidar por ello que el azar tiene sus propias leyes y nose reduce a pura arbilrariedad. Para nuestro caso hay, ciertamente, condiciones objetivas y subjelivas que podrían hacer pensar en la probabilidad y no sólo en la posibilidad de una insurrección popular. Pero estas condiciones no son suficientes para causar o delerminar la insurrección, porque hay también otras condiciones objetivas y subjetivas, que introducen un exponente muy elevado de indeterminación y de casualidad. Ahora bien, la casualidad puede buscarse y favorecerse, pero no 
puede contarse con ella de forma irresponsable ni dogmálica, sobre lodo, cuando la globalidad de los hechos, y no sólo un conjunto sectorial de los mismos, se resiste tercamente a las hipótesis y a los deseos insurreccionales ${ }^{(-1) !}$."

La historia, como lo muestra Ellacuría admite ciertamente un margen de creatividad, de innovación, por parte del sujeto, pero no se acopla ciegamente a lo que este sujeto pueda desear. La historia ofrece, por así decirlo, al sujeto una estructura de posibilidades con las cuales éste debe de partir. Tomar en cuenta cuál es la estructura de esas posibilidades en cada caso concreto permite llegar a análisis más exactos de la realidad histórica. Tal parece que el movimiento revolucionario perdió de vista esto en reiteradas ocasiones. Lo demuestra la forma en que el FMLN concibe el problema de la violencia terrorista. El terrorismo se ejerció cuando la guerrilla hizo objetivo militar de personas que no participaban directamente del enfrentamiento armado - aunque ello no implicara que pudieran tener simpalías hacia el bando contrario, o que pudiesen colaborar con éste-, así como de la infraestructura económica. Señala Ellacuría que ese lipo de violencia solamente contribuía a la violación de los derechos humanos en el pais: "Unas veces estas acciones van contra las instalaciones civiles (casas, negocios, industrias, cosechas, ganados, etc.), pero otras van contra las personas (alcaldes u otros personajes públicos e incluso, presumiblemente, personas civiles sin mayor significación político-militar). EI FMLN no se recata en aceptar actos violentos contra los buses, contra las casas particulares, contra los comercios, elc. Ha reconocido también algunos ajusticiamientos y, respecto de otros asesinatos, nos los ha desmentido públicamente..." ".omo se parte del supuesto que la historia está del lado del proyecto revolucionario, "el FMIN se obnubila al no medir rexactamente el resultado de sus acciones, cuando atiende sólo a lo positivo de ellas, sin considerar lo negativo que comportan tanto para el proceso como para la apreciación del mismo por una gran parte del pucblos..". Otro ejemplo: cuando se da el golpe militar de 1979, las organizaciones de masas intentan inducir un levantamiento insurreccional, con el consabido fracaso: "Sin esperar a los hechos y sin medir las posibilidades reales, el Frente de Acción Popular Unificada y las Ligas Populares se lanzaron a acciones inconsultas y suicidas, que luego malamente han podido disculpar, no digamos justificar "a". Su recomendación es clara: es necesario partir del criterio del bienestar de las mayorias: "Las organizaciones populares deben aprender a no usar el nombre del pucblo en vano y a no hacer en nombre del pucblo cosas que no las favoreeen: ni al pucblo en general, ni siquiera al pucblo más consciente"

Los análisis voluntaristas y las prácticas negativas podrían conducir al movimiento revolucionario a enajenarse del objetivo primordial: la lucha por la liberación, y convertirlos en meros movimientos preocupados por la loma del poder como un fin en sí mismo. Cuando se da el golpe de estado de octubre de 1979, se abre para el país una oportunidad de imporlantes transformaciones históricas. El golpe, protagonizado por la juventud militar, derrocó al Cieneral Romero y

Fundamentos filosóficos de la critica ellacuriana al movimiento revolucionario 
dio esperanzas de superar la hegemonía castrense sobre la sociedad. Ellacuría hizo una serie de comentarios reunidos bajo el título Una revolución necesaria. En esos comentarios, hizo una serie de llamados de atención a la izquierda, en el sentido de no desnaturalizar su lucha, de no perder de vista el objetivo histórico de lograr la liberación de las mayorías: "Io que se necesila es un cambio radical en la estruclura económica y en la estruclura polílica; en la estructura económica, haciendo parlícipes de la propiedad y de la gestación de los bienes produclivos a la mayoría hoy desposeida, y en la estructura polílica, haciendo partícipes del poder a las mayorias hoy marginadas ${ }^{6 .}$. En vez de proclamar consignas revolucionarias, la izquierda estaba llamada a recordar que "lo que ha de haber no es mística revolucionaria, sino convicción revolucionaria. Convicción nacida de ver que no hay otra salida para nuestro atormentado pais. Una revolución que no necesita de slogans, ni de gritos demagógicos, precisamente porque es una necesidad. Una necesidad perentoria, una necesidad que no puede esperar ${ }^{\text {the" }}$.

Finalmente, Ellacuría critica la relación entre el movimiento revolucionario y las organizaciones populares. Esta relación tiene un carácter verticalista, por cuanto el movimiento revolucionario se considera "vanguardia" de los cambios revolucionarios, mientras que las organizaciones populares son relegadas a la categoría de simples "masas", que desempeñan un papel auxiliar y deben ser conducidas por la "vanguardia histórica". Esto contradice la concepción ellacuriana de liberación - liberación para todos-, que se entiende como posibilitación de posibilidades de realización humana. Un modelo de liberación que parte de la subordinación de los desposeídos a los que se pretende liberar, cac en una aporía insostenible.

Con las masas, las vanguardias establecen una relación (jue no puede calificarse menos que paternalista y utilitaria: "Las masas para el FMLN o para el sandinismo - las lurbas divinas- no son, en la práctica, más alli de la teoría y de la retórica, ni los sujetos hegemonizantes ni los autodestinatarios del proceso histórico, sino, en el mejor de los casos, aquellas por quienes se mira y cuida, aquellas que justifican en su necesidad opresiva y represiva la revolución, aquellas que participan subordinadamente en los procesos sociales, políticos y militares; en el caso de El Salvador, las masas se diferencian de la guerrilla propiamente tal y difícilmente se hacen presentes en la alta dirigencia de las organizaciones que la conducen y que establecen cuál va a ser la estralegia, la tíctica y aun la maniobra; esto no (juila para que sean respeladas y para que se busquen los mejores bienes para ellas, siempre que estos no pongan, a la corla o a la larga, en peligro la hegemonía del partido y de su vanguardia" ${ }^{67 . "}$.

Este papel subordinado conduce a las organizaciones populares a desnaturalizarse: a perder contacto con las necesidades concretas de los sectores desposeídos que las crearon. En el caso salvadoreño, en el período comprendido entre 1975 y 1982, esto condujo a un activismo de corte militarista, en el cual las organizacio- 
nes populares se veían como un trampolín para saltar a la guerrilla. Ello se tradujo en el debilitamiento de dichas organizaciones y en la desaparición del movimiento de masas del espectro político del país. La historia se repitió a linales de los ochenta. En 1986, se da una reactivación del movimiento de masas, pero no se superó el carácter hegemonista de sus relaciones con el movimiento revolucionario, lo cual condujo al debilitamiento y a la pérdida de credibilidad por parte de las organizaciones populares, cosa que aún ahora dista de haber superado.

Las organizaciones populares contribuyen a la liberación desde su especificidad. Anulan su potencial liberador si convienen en subyugarse a entidades externas a ellas: "dar por sentado que lo bueno para el país y para las masas es un determinado proyecto político y económico, séa éste el de una revolución que deba ser propulsada por una alianza obrero-campesina, o sea el de un proceso democrálico, en el cual, a través del juego de los partidos, se llegarí al hien general, y que, por lo tanto, los movimientos de masas han de somelerse a esos proyectos y han de subordinarse a los conductores de los mismos, las organizaciones polílico-militares o los partidos, es confundir lo secundario con lo primario y es, en el fondo, menospreciar la dignidad y la voluntad efectiva de las masas. Suele recurrirse a la historia, cuando no a postulados más o menos científicos, para desvirtuar la capacidad de las masas en la búsqueda y encuentro de lo que es mejor para ellas y, consecuentemente, de lo que es mejor para la mayoria de la nación. Pero el recurso a la historia lambién está listo para probar los catastróficos resultados que han dado, en distintos paises, la confianza irrestricta en el sistema de partidos o la conducción no equilibrada por parte de representaciones artificiales del prolelariado o de las mayorías populares ${ }^{\text {s.". }}$.

Las organizaciones populares contribuyen a la liberación por cuanto responden a necesidades y circunstancias concretas de distintos sectores de la población. Al perder su especificidad, pierden lambién la oportunidad de responder por su realidad, de cuestionar desde su perspectiva a las estructuras opresoras y de proponer vías y alternativas de lucha que enriquezcan el proceso liberador. En suma, pierden la oportunidad de constituirse en prolagonistas -autores y actores- de la liberación. Pretender alcanzar la justicia y la liberación sin contribuir desde la propia especificidad es ilusorio. Lo único que se logra es cambiar determinadas estructuras políticas o socioeconomicas, pero sin tocar a fondo el problema de la falla de liberlad y justicia para lodos: para individuos y colectividades, para individuos y para mayorias.

\section{Conclusión}

El pensamiento filosófico de Ellacuria ofrece a todos aquellos que estin comprometidos en la lucha por la liberacioin de las mayorias una perspectiva crítica e integral. Más que una guia operativa para la accicin, ofrece elementos que fortalecen un análisis integral de la realidad y llama a no perder de vista la

Fundamentos filosóficos de la crítica ellacuriona al movimiento revolucionario 
perspectiva ética que debe prevalecer en todo proceso de liberación: la premisa de que no puede haber libertad para todos si no hay justicia para todos.

Los planteamientos del filósofo asesinado en 1989 son un sugestivo Ilamado a ser revolucionarios en un sentido más pleno: revolucionarios por estar comprometidos con la verdad. Revolucionarios, por hacer un ejercicio sistemático de la crítica contra toda tergiversación de la realidad que desenmascara dinámicas opresivas, sean estas de un signo ideológico o de otro. Revolucionarios, por hacer de preocupaciones éticas el punto de partida de sus acciones y por asumir los desafíos de una realidad que es, a todas luces, compleja y abierta, que no posee rutas seguras y que también ofrece posibilidades que entran en juego en el desafío de la liberación.

La crílica ellacuriana no desestima la contribución que el movimiento revolucionario ha dado a la húsqueda de la justicia social. Si se han registrado avances en el país en lo tocante a democracia formal, eso ha sido, en buena medida, gracias al sacrificio de las personas que integraron ese movimiento revolucionario. No obstante, el país está lejos de haber alcanzado la plena libertad basada en la justicia para todos. La izquierda no ha articulado propuestas coherentes para alcanzar ese objetivo y ha perdido lodo lo que tenía de cuestionador de la opresión en dispulas de poder. El pensamiento liberador no puede cometer los mismos errores ni caer en las mismas insuficiencias que se dieron en el pasado. Este es un contexto histórico influido en alto grado por la globalización capitalista y en sus nuevas formas de opresión y dominación de la humanidad. Con más razón, los nuevos proyeclos de liberación deben buscar puntos de partida más integrales y deben actuar en función de la nueva realidad mundial. El llamado ellacuriano a apegarse a la realidad a la hora de hacer análisis es importante sobremanera.. No se puede responder adecuadamente a un contexto mundial complejo, en el que los límites nacionales han sido sobrepasados, si se pretende que la verdad de la liberación la tienen unos cuantos iluminados. A la globalización opresora, el movimiento de liberación debe responder posibilitando la participación democrálica y el protagonismo de más sectores sociales que, desde sus propias necesidades e identidades, pueden cuestionar las distintas estrucluras de dominación. De esta manera, los movimientos liberadores se habrán puesto, como urgía Ellacuria, "a la altura de los licmpos".

\section{Bibliocikni:in}

- Ellacuría, Ignacio:

LII3R()S:

- Filosofía de la realidad histórica. UCA Editores, San Salvador, 1990).

- Veinte años de historia én El Sal'ador (1969-1989). Escritos politicos, Volúmenes I y II. UCA Editores, San Salvador. 1993. 
Articulos:

- Liberación. Revista Latinoamericana de Teología, Sepliembre-Diciembre de 1993, Año $X, N^{\circ} 30$, p. 213 y ss.

- Teología de liberación y marxismo. Revista Lalinoamericana de Teología, Mayo-Agosto de 1990, Año VII, N²0, pp. 109 y ss.

- González, Antonio: Aproximación a la obra filosófica de Ignacio Ellacuria. ECA, Noviembre-Diciembre de 1990, $N^{\circ}$ 505-5()6, pp. 979 y ss.

- Samour, Héctor: Filosofia y liberad, en Ignacio Ellacuria, "Acpuella liheread esclarecida", Jon Sobrino y Rolando Alvarado (eds.) UC.A Edilores, San Salvador, 1999.

Voluntad de liberación. (iénesis y constitución del proyecto de filosofía de liberación de Ignacio Ellacuría. Tesis doctoral, Facultad de (iencias y Humanidades de la Universidad Centroamericana "José Simeón Cañas", San Salvador, 2000.

- Zubiri, Xavier: La dimensión histórica del ser humano, en Realitas I. Trabajos del Seminario Xavier Zubiri 1972-1973. Sociedad de Estudios y Puhlicaciones, Madrid, 1974, pp. 11 y ss.

Notas

1. Cfr. La dimensión histórica del ser humano, de Xavier Zuhiri. en Realitas. Tomo I. p. 12.

2. Cfr., de Héctor Samour, Voluntad de liberación. (icinesis y constitución del proyecto de liberación de Ignacio Ellacuria, p. 127.

3. Zuhiri, Op. cir., p. 12.

4. Cfr., de lgnacio Ellacuria, Filosofia de la realidad histórica, p. 317.

5. Ídem.

6. Citado por Antonio González en Aproximación a la obra filossófica de Isnacio Ellacuria, ECA $N^{\circ}$ 505-506, Noviembre-Diciembre de 19(9), p. 982. I.a cilia de Zubiri pertenece a Inteligencia senticnte.

7. Cfr. Ellacuria, Op. cit., pp. 64-65.

8. Cfr. Filosofia y libertad, en Ignacio Ellacuria, "aquella libertad cesclarecida", p. 111.

9. Filosofia de la realidad histórica, p. 4)2.

10. Ibid, p. 545.

11. "O, dicho, desde otro punto de vista", en el original.

12. Ídem.

13. "Continuamente", en cl original.

14. Ihid, p. 498.

15. Ihid., p. 521

16. Ibid, p. 539.

17. Citado por Ellacuría en Ihid, p. 548. La cilit pertenece a La dimensión histórica del ser humano.

18. Ihid, p. 550.

19. Ihid, pp. 595-596. 
20. Ihid, p. 5\%6.

21. idem.

22. C'Tr. Funcion liheradora de' la filosofia, en Veinte arios de historia c'n lil Sal'ador (1969-1989). Escritos politicos, Tomo I. pig. 111.

23. Clr. Filosofia y lihortad, Op. cit., p. 116.

24. Ilsid, p. 201.

2.5. Ihid, p. 207.

26. Iidem.

27. idem.

28. Filosofia de la realidal histórica, p. 56.3.

29. (ilado por Samour en Fillosoffica y lihertad, op. cit., p. 13.3. Lal cita de I:llacuria proviene del ensiyo lin torno al concepto $v$ a la idea de liberación.

30. Cilado por Samour en Volumed de liberacioin. p. 23.3. La cilal de Ellacuria proviene de Teorias econcimicas y relación entre cristianismo y socialismo.

31. CTr. Funcioin liberadora de la filosofia. en Op. cit., p. 114.

32. (Tr. Liheración, Revista Latinoamericanal de Teologia, Año X, $n^{\circ}$ 30. p. 217. Las cursivals son miass.

33. Ihid, p. 22.3.

34. Ihid, p. 215 .

35. Cir. Teología de liheración y marxismo, Revista Lalinoamericana de Teologia, Año VII, $\mathrm{N}^{\circ} 20$, pp. 133-134.

36. Ihid, p. 1.34 .

37. Finción liheradora de la filosofia. ()p. (it.. pp. 12()-121.

38. Liheración., p. 222.

39. Ihid, p. 22.3.

40. Filosoffia y lihertad, (Op. cit.. p. 1.37.

41. Liheración, p. 222.

42. Función liheradora de la filossofia, ()p. cit., p. 118.

4.3. Lihcración, p. 224.

44. idcm.

4.5. idem.

46. ide'm.

47. Ihid, p. 225.

48. Cilado por Luis Armando Gonziilez en Aproximación al pensamiento de Octavio)

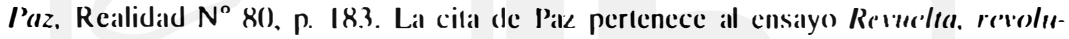
cioin, rehelisin.

49. Léasc, a este respecto, Inniversidad y politica. en Veimte anos de historia i'n l:l Salvador (1960-1980). Escritos politicos, Tomo l. p. 17 y ss.

50. Cir. La teologia de la liberación fre'nte al cambios sociohistericico e'n America Latina. en Veinte años de historia e'n lil Salvador. Tomo l, p. 322.

51. Ihid, p. 323.

52. Ihid, p. 327.

5.3. idem.

54. Ihid, pp. 327-328. Las cursivals son mias.

55. Ihid, p. 328 .

56. La desmitificacion del marxismo, en Veinte anos de historia e'n l:I Sall'ador. Tomo I. p. 284 . 
57. idcm.

58. ide'm.

59. Ihid, p. 286.

60). Recrudecimiento de la violencia a'n l:I Salvador, en Veinte anos de historia e'n EI Salvador, Tomol, pp. 477-478.

61. Visperas violentas, cn ()p. cit., p. 489.

62. Ihid, p. 492.

63. Una revolución necesaria, en Veinte aioss de historia a'n l:I Saltador. Tomo II, p. 824.

64. Ihid, p. 82.5 .

6.5. Ihid, p. 821 .

66. Ihid, р. 82().

67. La cuestion de las masas, en Veinte anos de historia c'n l:I Saliador. Tomo II, p. 779.

68. Ihid, p. 79)1. 